\title{
CORRESPONDENCE
}

\section{NOTE ON BLOOD-PRESSURES}

(To the Editors of the Journal of the Institute of Actuaries)

SIRS,

It has been the practice of this Company for many years to record blood-pressure readings in connection with applications for assurance. An analysis of blood-pressures has recently been made which would seem to establish that significant differences exist between bloodpressures of assured lives living in the British Isles and those of assured lives living in the United States. I am not aware that tables of diastolic blood-pressures, which some authorities consider of more importance than systolic blood-pressures, and blood-pressures of female lives, based upon assured lives resident in the British Isles, have previously been published. I am submitting the complete results, therefore, in the hope that you will consider them of sufficient value for publication in the Fournal.

The results are based upon blood-pressure readings for 6377 male lives and 21 6 female lives taken in the three years r930-32, in cases in which the assurance was issued at standard rates and in which the first premium was paid. The data included corresponds therefore with the data on which Dr Hunter's blood-pressures were based with regard to type of business, and since the Company issues instructions to its medical examiners under which the diastolic pressure must be taken at the beginning of the $5^{\text {th }}$ phase, it follows that the average readings for both systolic and diastolic pressures now submitted may be compared with Dr Hunter's readings ( $\mathscr{T}$. I.A. Vol. LVII). The differences produced may indicate real differences between the blood-pressures in this country and those in the United States. There are, however, other factors which might vitiate any conclusions, e.g. Dr Hunter's readings were taken during the years I 906 to I920, whereas those now submitted were taken during $193^{\circ}$, I93I and $193^{2}$; underwriting rules might have been different, etc., but allowance cannot be made for these.

It will be seen that Dr Hunter's systolic pressures are $3-4 \mathrm{~mm}$. lower than those now submitted and his diastolic pressures are $\mathrm{I}-2 \mathrm{~mm}$. lower, the differences remaining about the same at all ages between 20 and 60 and also the same for male and female lives.

When considering differences between the new systolic pressures and Mr Orr's (T.F.A. Vol. XIII, p. I8I) and Mr Recknell's ( $7 . I . A$. Vol. LXIII, p. 549), variations in the data included and the method of taking the blood-pressure must be kept in mind. Apparently Mr Orr included 
Table of blood-pressures obtained from the standard paid-for business of the Sun Life Assurance Company of Canada issued in the British Isles in the years $193^{\circ-32}$.

\begin{tabular}{|c|c|c|c|c|c|c|c|c|c|}
\hline \multirow{2}{*}{ Age } & \multicolumn{2}{|c|}{ Males } & \multicolumn{2}{|c|}{ Females } & \multirow{2}{*}{ Age } & \multicolumn{2}{|c|}{ Males } & \multicolumn{2}{|c|}{ Females } \\
\hline & Syst. & Diast. & Syst. & Diast. & & Syst. & Diast. & Syst. & Diast. \\
\hline 20 & 123 & $8 I$ & I 20 & 80 & 40 & 129 & 84 & 127 & 84 \\
\hline I & 123 & $8 \mathrm{I}$ & 120 & 80 & I & 129 & 85 & 128 & 84 \\
\hline 2 & 124 & 82 & I 21 & 80 & 2 & 130 & 85 & 128 & 84 \\
\hline 3 & 124 & 82 & I $2 \mathrm{I}$ & 80 & 3 & 130 & 85 & 129 & 84 \\
\hline 4 & 125 & 82 & I 21 & 80 & 4 & 130 & 85 & 129 & 85 \\
\hline 25 & 125 & 82 & $\Upsilon 22$ & 80 & 45 & I3 I & 85 & 130 & 85 \\
\hline 6 & 125 & 83 & 122 & $8 I$ & 6 & $\mathrm{I}_{3} \mathrm{I}$ & 85 & 130 & 85 \\
\hline 7 & 1 26 & 83 & 122 & $8 I$ & 7 & I3I & 86 & I3I & 85 \\
\hline 8 & 126 & 83 & 123 & $8 \pi$ & 8 & 132 & 86 & I3 I & 86 \\
\hline 9 & 126 & 83 & 123 & $8 I$ & 9 & 132 & 86 & 132 & 86 \\
\hline 30 & 126 & 83 & 123 & 81 & 50 & 133 & 86 & I 32 & 86 \\
\hline I & I 27 & 83 & 124 & 82 & I & I 33 & 86 & I33 & 86 \\
\hline 2 & 127 & 83 & I 24 & 82 & 2 & I34 & 86 & I 34 & 87 \\
\hline 3 & 127 & 84 & 124 & 82 & 3 & I34 & 87 & I34 & 87 \\
\hline 4 & 127 & 84 & 125 & 82 & 4 & I 35 & 87 & I35 & 87 \\
\hline 35 & 128 & 84 & 125 & 82 & 55 & I35 & 87 & I 35 & 87 \\
\hline 6 & 128 & 84 & 126 & 83 & 6 & I35 & 87 & I 36 & 88 \\
\hline 7 & 128 & 84 & 126 & 83 & 7 & I36 & 87 & 136 & 88 \\
\hline 8 & 129 & 84 & 127 & 83 & 8 & I 36 & 87 & I 37 & 88 \\
\hline 9 & I 29 & 84 & 127 & 83 & 9 & I37 & 88 & $13^{8}$ & 89 \\
\hline & & & & & 60 & I 37 & 88 & $\mathrm{I}_{3}^{8}$ & 89 \\
\hline
\end{tabular}

Comparison of figures in foregoing table with those previously published.

\begin{tabular}{|c|c|c|c|c|c|c|c|c|c|c|}
\hline \multirow{4}{*}{ Age } & \multirow{2}{*}{\multicolumn{4}{|c|}{$\begin{array}{l}\text { Sun Life of Canada } \\
\text { (business in British } \\
\text { Isles I930-32) }\end{array}$}} & \multirow{2}{*}{\multicolumn{4}{|c|}{ Hunter }} & \multirow{3}{*}{$\frac{\text { Orr }}{\text { Males }}$} & \multirow{3}{*}{$\begin{array}{c}\text { Recknell } \\
\text { Males } \\
\text { and } \\
\text { females }\end{array}$} \\
\hline & & & & & & & & & & \\
\hline & \multicolumn{2}{|c|}{ Males } & \multicolumn{2}{|c|}{ Females } & \multicolumn{2}{|c|}{ Males } & \multicolumn{2}{|c|}{ Females } & & \\
\hline & Syst. & Diast. & Syst. & Diast. & Syst. & Diast. & Syst. & Diast. & Syst. & Syst. \\
\hline 20 & 123 & $8 \mathrm{I}$ & 120 & 80 & 120 & 79 & I 16 & 77 & 124 & 122 \\
\hline 25 & I 25 & 82 & 122 & 80 & I2I & 80 & II 8 & 78 & 125 & 123 \\
\hline 30 & 126 & 83 & 123 & $8 \mathrm{I}$ & 123 & $8 I$ & 119 & 79 & 126 & 124 \\
\hline 35 & 128 & 84 & 125 & 82 & 124 & 82 & 120 & 80 & 127 & 126 \\
\hline 40 & I 29 & 84 & 127 & 84 & 125 & 83 & 124 & 82 & 129 & 127 \\
\hline 45 & I3 I & 85 & I 30 & 85 & 127 & 84 & 127 & 84 & 130 & 130 \\
\hline 50 & 133 & 86 & I32 & 86 & 129 & 85 & 130 & 85 & I33 & r33 \\
\hline 55 & 135 & 87 & I35 & 87 & I3I & 86 & 132 & 87 & I35 & I36 \\
\hline 60 & I 37 & 88 & 138 & 89 & r 34 & 87 & I34 & 87 & I 38 & 140 \\
\hline
\end{tabular}




\section{Correspondence}

standard male lives only, whereas Mr Recknell included all cases applied for. Also some of the readings in Mr Recknell's cases were taken by palpation which gives lower pressures than those given by auscultation, the method used for all cases in the other three analyses. It is not surprising, therefore, to find a very close agreement between Mr Orr's figures and those now submitted. The inclusion by Mr Recknell of declined, postponed and cases accepted upon special terms would probably not affect the pressures materially at ages under 40 , as there are relatively few substandard cases with high blood-pressures at these ages, but would have the effect of increasing the pressures by an amount increasing as the age increases at ages over 40 . It must be remembered, however, that there are two factors both tending to reduce Mr Recknell's pressures at all ages, viz. the palpation method of taking some of the readings and the inclusion of female lives. Accordingly it is not surprising to find that Mr Recknell's pressures are lower than those now submitted at the young ages and are not higher until age $5 \mathrm{I}$.

It will be seen that both systolic and diastolic pressures are lower for female lives than for male lives at the young ages, but that the difference decreases as the age increases until the pressures become approximately the same for ages over $5^{\circ}$. The same tendencies will be observed in Dr Hunter's readings for female lives.

This analysis has been made by $\mathrm{Mr}$ A. B. Chiles, A.I.A., of the Mortality Department of the Company's London Administrative Office.

I am, Sirs, etc.

I. A. MILLER

Resident Actuary

Sun Life Assurance Company of Canada,

2 Cockspur Street, S.W. I

I ith $\mathcal{F u l y ,} 1934$ 